\title{
INFLUÊNCIA DA ÉPOCA DE SEMEADURA E DO MANEJO DA PARTE AÉREA DE MILHETO SOBRE A SOJA EM SUCESSÃO EM PLANTIO DIRETO(1)
}

\author{
LEANDRO BORGES LEMOS ${ }^{(2)}$; JOÃO NAKAGAWA ${ }^{(2)}$; CARLOS ALEXANDRE COSTA CRUSCIOL ${ }^{(2)}$; \\ WARLEI CHIGNOLI JÚNIOR ${ }^{(2)}$; TIAGO ROQUE BENETOLI DA SILVA ${ }^{(2)}$
}

\begin{abstract}
RESUMO
Uma das grandes limitações do plantio direto é a produção e manutenção da cobertura vegetal. Por esse motivo, o milheto tem-se constituído em boa opção de cultivo no inverno, gerando palhada com decomposição mais lenta viabilizando esse sistema de produção. O objetivo do experimento foi estudar a cultura do milheto em três épocas de semeadura (5/3, 25/3 e 19/4/99), sob condições de sequeiro, e a ceifa da parte aérea (ceifa a cada florescimento e retirada do resíduo vegetal; ceifa a cada florescimento e permanência do resíduo vegetal; ceifa no florescimento e retirada do resíduo vegetal; ceifa no florescimento e permanência do resíduo vegetal e livre crescimento, sem ceifar), bem como seu efeito na produção da soja cultivada na seqüência. Pode-se concluir que o milheto semeado em março e submetido à ceifa na época de cada emissão da panícula proporcionou as maiores produções de matéria seca dessa espécie. Tal cultura demonstrou grande capacidade na produção de matéria seca e, quando semeada em 5 de março e 19 de abril, propiciou as maiores produtividades da soja cultivada em sucessão.
\end{abstract}

Palavras-chave: Pennisetum typhoides, Glycine max, ceifa.

\author{
ABSTRACT \\ SOWING TIMES AND MILLET CROP RESIDUES ON SOYBEAN IN SUCCESSION \\ UNDER A NO-TILLAGE SYSTEM
}

Crop residues management must be adequate in no-tillage systems. Winter millet has shown to produce crop residues of slow decomposition in adequate amounts. The experiment aimed to study growing millet in three sowing times (5/Mar, 25/Mar and $19 \mathrm{Apr} / 99$, under rainfed conditions, five types of crop cut management (at each flowering and no residues; at each flowering with residues; at flowering and no residues; at flowering with residues, no cut) and its effects on soybean yield, grown in succession. It was concluded that millet sown in March and cut at the time of each flowering provided the greatest amounts of crop residues. In general, millet produced large amounts of crop residues and for the 5/Mar and 19/Apr sowing dates, provided the greatest yields for soybean in succession.

Key words: Pennisetum typhoides, Glycine max, cut management.

( $\left.{ }^{1}\right)$ Recebido para publicação em 10 de outubro de 2002 e aceito em 25 de agosto de 2003.

$\left({ }^{2}\right)$ Departamento de Produção Vegetal - FCA/UNESP, Caixa Postal 237, 18603-970 Botucatu (SP). E-mail: leandrobl@fca.unesp.br 


\section{INTRODUÇÃO}

Dentre as culturas anuais cultivadas nos cerrados, a soja constitui-se na principal exploração agrícola, seguida pelo milho, arroz, algodão e feijão. Essas culturas, quando desenvolvidas em sistema convencional, demandam grande número de operações de preparo de solo, contribuindo para a redução de sua capacidade produtiva, causada pelas perdas e mudanças nas propriedades biológicas, físicas e químicas do solo.

No sistema convencional, muitos agricultores efetuam o preparo primário do solo com uma gradagem imediatamente após a colheita da soja, com o objetivo de incorporar os restos culturais e manter a área com baixa infestação de plantas daninhas. Assim, o solo permanece sem cobertura e, na maioria das vezes, fica completamente exposto, sem vegetação, durante o período da entressafra, favorecendo a ocorrência da erosão e acelerando o processo de degradação. A solução para o problema seria o estabelecimento de uma cultura na entressafra da cultura de verão que proporcionasse cobertura vegetal suficiente para cobrir o solo nesse período. $\mathrm{O}$ desenvolvimento de técnicas que permitam, em regiões com inverno seco, o estabelecimento de sistemas de produção agrícola, que sejam ao mesmo tempo econômicos e conservacionistas, é de suma importância dentro da agricultura moderna.

Com a adaptação de espécies adequadas, tolerantes às restrições ambientais da região dos cerrados e o desenvolvimento de técnicas de cultivo apropriadas será possível o estabelecimento de sistemas de produção que permitam uma agricultura econômica e sustentável nessas regiões, o que tem sido um grande desafio à pesquisa agronômica.

A proteção do solo com cobertura vegetal tem sido o objeto de estudos, notadamente em regiões de clima temperado (DEDECEK et al, 1986; Castro et al, 1986; Silva et al, 1986; Lopes, et al., 1987; LOMBARDI Neto et al., 1988; Derpsch e CAlegari, 1992 e Pereira, 1990). Nas regiões de clima tropical, poucos são os trabalhos de pesquisa nessa linha, e os resultados têm mostrado que a maior limitação é a rapidez com que a massa vegetal se decompõe (PEREIRA, 1990 e LANDERS, 1995).

O milheto tem-se constituído em boa opção de cultivo no inverno, em regiões de cerrado como em Mato Grosso e Mato Grosso do Sul, apresentando, nesse período, área cultivada de 600.000 e 200.000 ha respectivamente (SALTON, 2001).

O sucesso da adaptação dessa cultura nos cerrados é devido à sua alta resistência à seca, adaptabilidade a solos de baixa fertilidade, capacidade de produção de restos vegetais, além de ser uma cultura de fácil instalação e desenvolvimento e excelente forrageira. Apresenta-se como alternativa valiosa na integração agricultura-pecuária, pois é altamente palatável, de grande capacidade de rebrota, e bom valor nutricional (SCALÉA, 1999).

O objetivo deste experimento foi estudar, sob condições de sequeiro, a cultura do milheto, em três épocas de semeadura, e a ceifa da parte aérea para posterior semeadura da cultura da soja.

\section{MATERIAL E MÉTODOS}

O experimento foi instalado em área da Faculdade de Ciências Agronômicas/UNESP, Câmpus de Botucatu (SP), anteriormente cultivada com guandu. O clima, de acordo com a classificação de Köppen, é do tipo Cfa subtropical com verões quentes e úmidos e invernos frios e secos. As coordenadas geográficas de referência são: Latitude Sul $22^{\circ} 49^{\prime} 31^{\prime \prime}$ e Longitude Oeste $48^{\circ} 25^{\prime} 37^{\prime \prime}$. A altitude do local é de 750 metros e a declividade, de $5 \%$.

O solo foi classificado como Nitossolo Vermelho Distroférrico (EMBRAPA, 1999). Em outubro de 1998, realizou-se a análise química do solo, de acordo com método descrito por RaIJ e QuAGGIO (1983), com os seguintes resultados: $8,1 \mathrm{mg} \cdot \mathrm{dm}^{-3}$ de fósforo; 25 g.dm ${ }^{3}$ de $\mathrm{MO} ; 4,5$ unidades de $\mathrm{pH}$ em $\mathrm{CaCl}_{2} ; 2,2 ; 20,1$; 8,$0 ; 64,7 ; 30,3 ; 95 \mathrm{~m} \mathrm{~mol}_{\mathrm{c}} \cdot \mathrm{dm}^{-3}$ de $\mathrm{K}, \mathrm{Ca}, \mathrm{Mg}, \mathrm{H}+\mathrm{Al}, \mathrm{SB}$, CTC respectivamente e $32 \%$ de saturação por bases, além de 6,$4 ; 1,0 ; 25,5$ e 28,7 mg.dm ${ }^{-3}$ de Cu, Zn, Mn e Fe na profundidade de 0 a $20 \mathrm{~cm}$.

Em novembro de 1998 foi aplicado, após a aração do solo, 3,0 t.ha ${ }^{-1}$ de calcário dolomítico com PRNT de 85\%, sendo incorporado por outra aração e duas gradagens. A adubação de semeadura constituiuse de $300 \mathrm{~kg} \cdot \mathrm{ha}^{-1}$ da fórmula comercial 8-28-16 + 0,4\% de Zn. A semeadura da soja foi realizada mecanicamente em 14 de dezembro de 1998, utilizando a cultivar IAC-17, no espaçamento de $0,50 \mathrm{~m}$, com 30 sementes por metro, sem inoculação.

Em 15 de fevereiro de 1999, a cultura foi dessecada com o herbicida (Glyphosate). Portanto, a soja cultivada não completou seu ciclo e objetivou apenas a uniformização da área experimental, para instalação posterior da cultura do milheto.

O delineamento experimental utilizado foi o de blocos casualizados, com cinco tratamentos, no caso, tipos de manejo do milheto, com quatro repetições. Cada época de semeadura foi avaliada como um experimento $\left(\mathrm{E}_{1}=05 / 03, \mathrm{E}_{2}=25 / 03\right.$ e $\left.\mathrm{E}_{3}=19 / 04\right)$. 
As parcelas de cada experimento foram representadas por diferentes manejos da parte aérea, sendo o manejo $1\left(\mathrm{M}_{1}\right)$ : ceifa a cada florescimento (considerando o florescimento da soqueira) e retirada do resíduo vegetal; manejo $2\left(\mathrm{M}_{2}\right)$ : ceifa a cada florescimento e permanência do resíduo vegetal; manejo $3\left(\mathrm{M}_{3}\right)$ : ceifa no florescimento e retirada do resíduo vegetal; manejo $4\left(\mathrm{M}_{4}\right)$ : ceifa no florescimento e permanência do resíduo vegetal e manejo $5\left(\mathrm{M}_{5}\right)$ : livre crescimento, até a produção de grãos, quando foi cortada somente a panícula, e o restante permanecendo no solo. Os manejos com retirada da fitomassa da área experimental $\left(\mathrm{M}_{1}\right.$ e $\left.\mathrm{M}_{3}\right)$ simulam a utilização do milheto para alimentação animal (silagem, por exemplo). Já os manejos com corte apenas no primeiro florescimento $\left(\mathrm{M}_{3}\right.$ e $\left.\mathrm{M}_{4}\right)$ têm como intuito a produção de forragem $\left(\mathrm{M}_{3}\right)$ e cobertura vegetal para o plantio direto $\left(\mathrm{M}_{4}\right)$, além de verificar o comportamento da rebrota do milheto até o fim de seu ciclo quanto à produção de resto vegetal, comparado aos manejos com ceifa em cada florescimento $\left(\mathrm{M}_{1}\right.$ e $\left.\mathrm{M}_{2}\right)$.

Ressalta-se que nos manejos $\mathrm{M}_{1}$ e $\mathrm{M}_{2}$ ocorreu mais de um corte, diferentemente de $\mathrm{M}_{3}$ e $\mathrm{M}_{4}$ quando se realizou apenas um corte ao longo do ciclo da cultura. As parcelas experimentais foram constituídas por 9,0 m de comprimento e 3,0 m de largura, ou seja, 27,0 $\mathrm{m}^{2}$ de área total, considerando como bordadura as duas linhas laterais e $0,5 \mathrm{~m}$ nas duas extremidades das linhas.

O milheto foi semeado mecanicamente, utilizando-se a cultivar BN-2, no espaçamento de $0,20 \mathrm{~m}$, com $25 \mathrm{~kg}$.ha- ${ }^{-1}$ de sementes, misturadas com superfosfato simples na quantidade de $375 \mathrm{~kg} \cdot \mathrm{ha}^{-1}$.

Durante o desenvolvimento da cultura do milheto avaliou-se a produção de matéria seca, número de colmos e área foliar. Para isso, por ocasião de cada florescimento, retirou-se ao acaso, três amostras de 0,5 $\mathrm{m}$ de comprimento em duas linhas da área útil de cada parcela experimental. De cada amostra, contou-se o número total de colmos e, posteriormente, subamostraram-se três plantas ao acaso, totalizando nove por parcela experimental. Dessas nove plantas, retiraram-se todas as folhas e, com o auxílio do medidor de área foliar, determinou-se a área foliar. Em seguida, as folhas e plantas foram secas em estufa máxima de $60^{\circ} \mathrm{C}$ até atingirem massa constante.

Em $1 .^{\circ}$ de outubro, coletaram-se todas as plantas de milheto contidas em duas linhas de $0,5 \mathrm{~m}$ de comprimento, para determinar a produção de matéria seca. Em seguida, triturou-se a cobertura remanescente (manejo final), com equipamento triton e posteriormente com aplicação de herbicida (Ghyphosate). Em 17 de novembro de 1999, a cultura da soja foi semeada, também no sistema de plantio direto, utilizando-se a cultivar EMBRAPA-48, no espaçamento de 0,60 m, com 30 sementes por metro. A demora entre o manejo final e a semeadura da soja foi devido à seca que ocorreu no período. A adubação de semeadura constituiu-se de $300 \mathrm{~kg} \cdot \mathrm{ha}^{-1}$ da fórmula 8-28-16 + 0,4\% de $\mathrm{Zn}$. Adicionou-se Carboxin + Thiram (200 SC) na dose de $250 \mathrm{~mL}$ do produto comercial para cada $100 \mathrm{~kg}$ de semente. Adicionou-se também solução contendo os micronutrientes Co $(0,01 \%)$ e Mo $(2,5 \%), 250 \mathrm{~mL} /$ $100 \mathrm{~kg}$ de semente. Por fim, adicionaram-se $300 \mathrm{~mL}$ de inoculante em formulação líquida (gel) para cada $100 \mathrm{~kg}$ de semente.

A colheita da soja realizou-se em 13 de abril de 2000, ou seja, 147 dias após a semeadura. A avaliação da produtividade de grãos e das demais variáveis estudadas na soja foi determinada nas quatro linhas centrais da área útil de cada parcela experimental.

Antes da colheita, realizou-se a contagem do número de plantas na área útil de cada parcela por hectare. Em seguida, coletaram-se 10 plantas na área útil de cada parcela, para verificar altura de plantas, altura da inserção da primeira vagem, componentes de produção (número total de vagens por planta, número de vagens normais por planta, número e porcentagem de vagens chochas por planta, massa de 100 grãos e produtividade de grãos).

As características do milheto e da soja foram avaliadas estatisticamente, considerando-se o delineamento de blocos casualizados com cinco tratamentos (manejos) e quatro repetições. Também foi realizada a análise conjunta para as três épocas de semeadura. Para efeito de análise, os dados obtidos em porcentagem e em contagem foram transformados em arc sen $(x / 100)^{1 / 2}$ e $(x)^{1 / 2}$ respectivamente; no entanto, os resultados são apresentados com os dados originais. As médias foram comparadas pelo teste de Tukey.

\section{RESULTADOS E DISCUSSÃO}

A cultura do milheto apresentou diferença de desempenho em seu desenvolvimento em função das épocas de semeadura. Dessa forma, as épocas $E_{1}$ e $E_{2}$ possibilitaram duas ceifas para os manejos $\mathrm{M}_{1} \mathrm{e} \mathrm{M}_{2}$, respectivamente em $30 / 4$ e $2 / 7$ para $\mathrm{E}_{1}$, em $28 / 05$ e $3 / 8$ para $E_{2}$ (Figura 1), enquanto a época mais tardia de semeadura $\left(E_{3}\right)$ proporcionou apenas uma ceifa, realizada em $5 / 8$. Observou-se ainda que o número de dias entre a semeadura e o início da emissão da panícula (florescimento, para realização da ceifa) variou em função da data de semeadura, sendo a maior diferença verificada entre $E_{2} e_{3}$. 
Essas diferenças devem ser atribuídas às temperaturas mais baixas sob as quais as plantas estiveram sujeitas em $\mathrm{E}_{3}$, durante a fase de desenvolvimento vegetativo, pois, de acordo com FerRARIs e NoRman (1976), este fator climático interfere no desenvolvimento do milheto.

Não se pode descartar o possível efeito da falta de chuva, observada, sobretudo, no estádio inicial de crescimento vegetativo, se comparado com as duas épocas anteriores de semeadura, tendo em vista a sensibilidade hídrica do milheto, conforme observado por SEIFFER e BARRETo (1977). Diferenças maiores puderam ser observadas na ocorrência do estádio de $100 \%$ de emergência da panícula, entre as três épocas de semeadura, no manejo $\mathrm{M}_{5}$, de livre crescimento.

Avaliando-se o número de colmos, a área foliar e a produção de restos vegetais por ocasião da primeira ceifa, nos manejos $\mathrm{M}_{1}, \mathrm{M}_{2}, \mathrm{M}_{3}$ e $\mathrm{M}_{4}$, para a média das três épocas de semeadura (Quadro 1) não se observou diferença entre os valores obtidos. Constatou-se diferença entre épocas de semeadura para os parâmetros área foliar e produção de restos vegetais, mas semelhança para número de colmos.

A maior produção de restos vegetais na primeira ceifa foi obtida na primeira época de semeadura, o que pode ser resultado do maior desenvolvimento das plantas, traduzido pela elevada área foliar e, conseqüentemente, melhores condições climáticas de temperatura e chuvas (Figura 1), em relação às demais épocas, considerando o comentado anteriormente (Ferarris e Norman, 1976; Seiffer e Barreto, 1977).

$\mathrm{Na}$ segunda ceifa, realizada apenas nos manejos $M_{1}$ e $M_{2}$, da primeira e da segunda época de semeadura $\left(E_{1}\right.$ e $\left.E_{2}\right)$, observou-se, novamente, semelhança entre os resultados de número de colmos, área foliar e produção de restos vegetais obtidos nos dois manejos, para a média de épocas, mostrando que nas duas épocas, a rebrota após a ceifa no início do florescimento (emissão de panícula) foi uniforme entre os tratamentos (Quadro 2). No entanto, observaram-se diferenças de área foliar e de produção de restos vegetais entre as épocas, com maiores valores para $\mathrm{E}_{2}$, apesar da semelhança do número de colmos, significando que o número de rebrotas foi semelhante nas duas épocas. Todavia, seu desenvolvimento foi menor na época $\mathrm{E}_{1}$ (menor área foliar), pela reduzida precipitação pluvial logo após a rebrota, se comparada com a verificada para $\mathrm{E}_{2}$ (Figura 1).

As chuvas que ocorreram em junho provavelmente tiveram pouca importância no crescimento das plantas (rebrotas) de $E_{1}$, pois a diferenciação das panículas já havia sido observada para a maioria delas, bem como para o número de folhas e porte da planta. Já para $\mathrm{E}_{2}$, como a chuva ocorreu no início da rebrota, favoreceu o crescimento, resultando em maior área foliar e produção de restos vegetais.

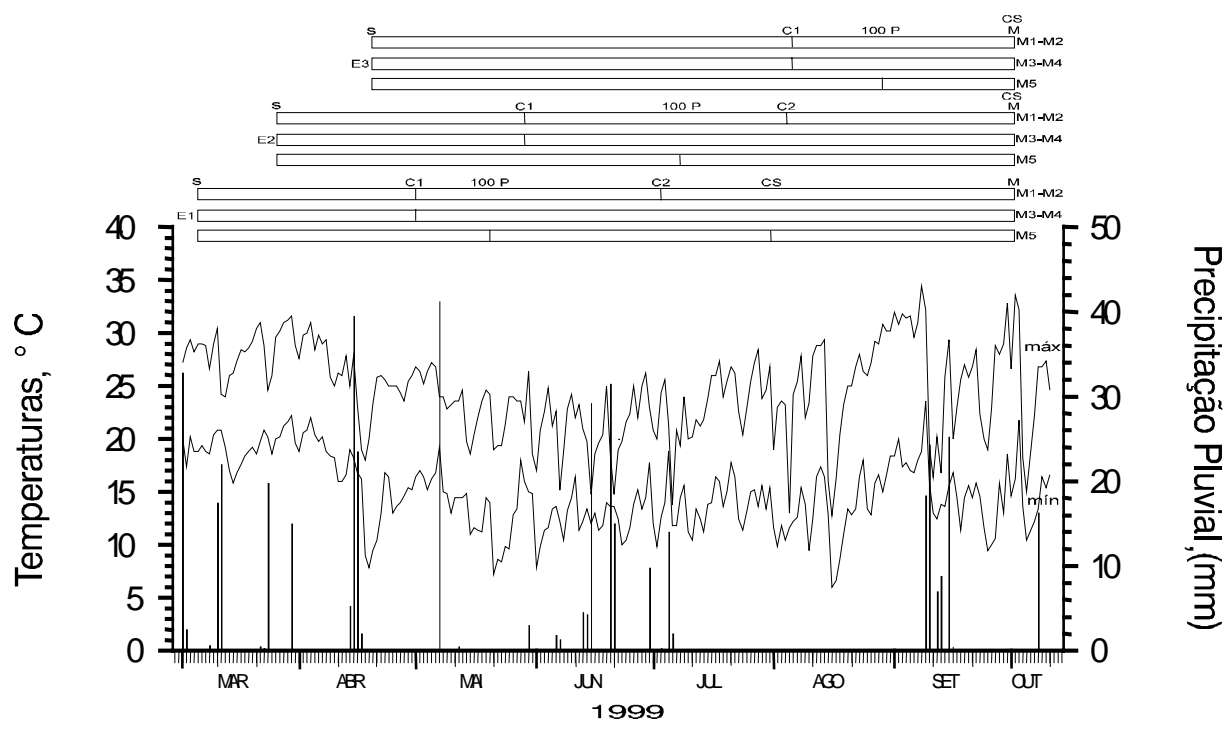

Figura 1. Ciclo cultural e épocas dos diferentes manejos de ceifa da parte aérea de milheto para três épocas de semeadura. Dados diários de precipitação pluvial e temperaturas máxima e mínima. E1, E2, E3 = épocas de semeadura; M1,..., M5 = manejos; C1, C2, M (manejo final) = ceifas; $100 \mathrm{P}=100 \%$ emergência de panículas; CS = colheita de sementes. 
Quadro 1. Análise conjunta das três épocas de semeadura $\left(\mathrm{E}_{1}, \mathrm{E}_{2}, \mathrm{E}_{3}\right)$ para número de colmos, área foliar e produção de restos vegetais de milheto, obtidos na primeira ceifa dos diferentes manejos da fitomassa $\left(M_{1}, M_{2^{2}}, M_{3^{\prime}}, M_{4^{\prime}}, M_{5}\right)$ de milheto. Botucatu, 1999

\begin{tabular}{|c|c|c|c|}
\hline Manejo/Época & $\begin{array}{l}\text { Número de } \\
\text { colmos por } \mathrm{m}^{2}\end{array}$ & Área foliar & Restos vegetais \\
\hline & & $\mathrm{cm}^{2}$ & $\mathrm{tha}^{-1}$ \\
\hline M1 & 388,6 a & 900,6 a & $6,5 \mathrm{a}$ \\
\hline M2 & $435,3 \mathrm{a}$ & $1.029,7 \mathrm{a}$ & 8,1 a \\
\hline M3 & $423,9 \mathrm{a}$ & 983,2 a & 8,0 a \\
\hline M4 & $411,7 \mathrm{a}$ & $1.006,2 \mathrm{a}$ & $7,9 \mathrm{a}$ \\
\hline M5 & índice $^{(1)}$ & - & - \\
\hline E1 & $469,8 \mathrm{~A}$ & $1.212,4 \mathrm{~A}$ & $9,4 \mathrm{~A}$ \\
\hline E2 & $378,7 \mathrm{~A}$ & 896,0 B & $5,9 \mathrm{~B}$ \\
\hline E3 & $396,0 \mathrm{~A}$ & 831,3 B & $7,5 \mathrm{~B}$ \\
\hline C.V. $(\%)$ & 26,0 & 26,3 & 24,4 \\
\hline
\end{tabular}

Médias na coluna, seguidas da mesma letra minúsculas para manejos e maiúsculas para épocas, não diferem entre si a 5\% de probabilidade pelo teste Tukey. ${ }^{(1)}$ Ceifa não realizada.

Quadro 2. Análise conjunta das três épocas de semeadura $\left(\mathrm{E}_{1}, \mathrm{E}_{2}, \mathrm{E}_{3}\right)$ para número de colmos, área foliar e produção de restos vegetais de milheto obtidos na segunda ceifa dos diferentes manejos da fitomassa $\left(M_{1^{\prime}}, M_{2}, M_{3^{\prime}}, M_{4^{\prime}}, M_{5}\right)$ de milheto. Botucatu, 1999

\begin{tabular}{lccc}
\hline Manejo/Época & $\begin{array}{c}\text { Número de } \\
\text { colmos por } \mathrm{m}^{2}\end{array}$ & Área foliar & Restos vegetais \\
\hline M1 & $544,6 \mathrm{a}$ & $\mathrm{cm}^{2}$ & 5,7 a \\
M2 & $492,1 \mathrm{a}$ & $350,0 \mathrm{a}$ & $5,2 \mathrm{a}$ \\
M3 & índice ${ }^{-1}$ & $344,4 \mathrm{a}$ & - \\
M4 & - & - & - \\
M5 & - & - & - \\
E1 & $554,6 \mathrm{~A}$ & $228,0 \mathrm{~B}$ & $3,1 \mathrm{~B}$ \\
E2 & $482,1 \mathrm{~A}$ & $466,5 \mathrm{~A}$ & - \\
E3 & - & - & A \\
C.V. (\%) & 16,8 & 19,1 & 22,1 \\
\hline
\end{tabular}

Médias na coluna, seguidas da mesma letra minúscula para manejos e maiúscula para épocas, não diferem entre si significativamente a 5\% de probabilidade pelo teste Tukey. ${ }^{(1)}$ Ceifa não realizada.

O início da emissão da panícula, tanto para as plantas como para as rebrotas, ocorreu em torno de dois meses após a semeadura ou a ceifa, para as épocas $E_{1}$ e $E_{2}$, mostrando a sensibilidade dessa cultivar ao fotoperíodo do outono/inverno (Figura 1), uma vez que se trata de espécie de dia curto para a maioria das cultivares estudadas (BURGER, 1984).

Ao se avaliar a produção de restos vegetais do milheto, por ocasião do manejo final da cultura (ceifa final), observou-se distinção entre os manejos para cada época de semeadura (Quadro 3). Assim, nas épocas $E_{1}$ e $E_{2}$, os manejos $M_{1}$ e $M_{2}$, que sofreram duas ceifas, apresentaram as menores produções de restos vegetais, enquanto o $\mathrm{M}_{5}$, de livre crescimento (para colheita de sementes), revelou os maiores valores nas três épocas.

Os manejos $\mathrm{M}_{3}$ e $\mathrm{M}_{4}$, com uma ceifa, apresentaram valores intermediários. Da mesma forma, em $\mathrm{E}_{3}$ os manejos $M_{1}, M_{2}, M_{3}$ e $M_{4}$, por terem sofrido uma ceifa anterior obtiveram menor resto vegetal que $M_{5}$, de livre crescimento. Dessa forma, a avaliação do resto vegetal produzido pelas plantas sem ceifa foi sempre maior que a da rebrota e esta mais elevada que a da segunda rebrota. 
Comparando-se a produção de fitomassa dentro dos tratamentos (Quadro 3) verifica-se que não houve diferença de produção para $M_{1}$ e $M_{2}$, entre as três épocas de semeadura, apesar de $\mathrm{E}_{1}$ e $\mathrm{E}_{2}$ terem sofrido duas ceifas pouco antes que a ceifa única de $\mathrm{E}_{3}$, justificando e possibilitando um crescimento semelhante ao das rebrotas (Figura 1).

Para $\mathrm{M}_{3}$ e $\mathrm{M}_{4}$, com ceifa única, o melhor desempenho foi para $E_{2}$, e o pior para $E_{3}$. Nessa, o período entre a ceifa e o manejo final foi mais curto, enquanto para $E_{2}, \operatorname{logo}$ após a ceifa, as condições de chuvas foram mais favoráveis para o crescimento da rebrota do que para $\mathrm{E}_{1}$, como comentado anteriormente. Para o manejo de livre crescimento $\mathrm{M}_{5}$, à medida que se atrasou a semeadura, a produção de fitomassa no manejo final foi menor. A maior produção de restos vegetais em $E_{1}$, no manejo 5, pode estar relacionada com o ciclo mais longo das plantas nessa época, pois em $30 / 7$, as panículas foram retiradas para colheita dos grãos, permanecendo as plantas até $\left(1 .^{\circ} / 10\right)$, quando se colheram as panículas das demais épocas $\left(E_{2}\right.$ e $\left.E_{3}\right)$. Observaram-se, também, reduções na produção de restos vegetais em outros trabalhos, devido ao atraso na semeadura de verão/outono (LiRA et al., 1977; WestPhalen e Jacques, 1978).

Ao se comparar a produção de resto vegetal nas diferentes épocas de ceifa $\left(\mathrm{C}_{1}, \mathrm{C}_{2}, \mathrm{C}_{3}\right)$ para os manejos $M_{1}$ e $M_{2}$, verificou-se que a primeira ceifa proporcionou maior produção que a segunda e a terceira (Quadro 4).

Quadro 3. Dados de produção de restos vegetais de milheto, obtidos por ocasião da ceifa final, antes da semeadura da soja, nos diferentes manejos $\mathrm{M}_{1}, \mathrm{M}_{2}, \mathrm{M}_{3}, \mathrm{M}_{4}, \mathrm{M}_{5}$, para cada uma das as três épocas de semeadura $\left(\mathrm{E}_{1}, \mathrm{E}_{2}, \mathrm{E}_{3}\right)$. Botucatu, 1999

\begin{tabular}{|c|c|c|c|}
\hline \multirow{3}{*}{ Manejo } & \multicolumn{3}{|c|}{ Épocas de semeadura } \\
\hline & E1 & E2 & E3 \\
\hline & \multicolumn{3}{|c|}{ Produção de restos vegetais } \\
\hline & \multicolumn{3}{|c|}{ t.ha ${ }^{-1}$} \\
\hline M1 & $3,2 \mathrm{c} \mathrm{A}$ & $2,0 \mathrm{~b} \mathrm{~A}$ & $2,8 \mathrm{~b} \mathrm{~A}$ \\
\hline M2 & $3,0 \mathrm{c} \quad \mathrm{A}$ & $1,9 \mathrm{~b} \mathrm{~A}$ & $3,0 \mathrm{~b} \mathrm{~A}$ \\
\hline M3 & $7,4 \mathrm{~b} \quad \mathrm{~B}$ & 11,4 a $A$ & $3,0 \mathrm{~b} \mathrm{C}$ \\
\hline M4 & $5,9 \mathrm{bc} \mathrm{AB}$ & 7,9 a A & $2,9 \mathrm{~b} \mathrm{~B}$ \\
\hline M5 & 15,6 a $\mathrm{A}$ & 11,7 a $B$ & 7,2 a $C$ \\
\hline C.V. $(\%)$ & 19,4 & 29,3 & 28,1 \\
\hline
\end{tabular}

Médias seguidas da mesma letra minúscula para manejo e maiúscula para épocas, não diferem entre si significativamente a 5\% de probabilidade pelo teste Tukey.

Quadro 4. Dados de produção de restos vegetais de milheto, obtidos nas três ceifas $\left(C_{1}, C_{2}, C_{3}\right)$, para os manejos $M_{1}, M_{2}$ e para as três épocas de semeadura $\left(\mathrm{E}_{1}, \mathrm{E}_{2}, \mathrm{E}_{3}\right)$. Botucatu, 1999

\begin{tabular}{|c|c|c|c|}
\hline \multirow{3}{*}{ Manejo/Época } & \multicolumn{3}{|c|}{ Ceifas do milheto } \\
\hline & $\mathrm{C} 1$ & $\mathrm{C} 2$ & $\mathrm{C} 3$ \\
\hline & \multicolumn{3}{|c|}{ Produção de restos vegetais } \\
\hline & & $-\mathrm{t} \cdot \mathrm{ha}^{-1}$ & 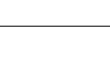 \\
\hline M1 & $6,5 \mathrm{~b} \mathrm{~A}$ & 3,8 a B & 2,7 a B \\
\hline M2 & 8,1 a $A$ & 3,5 a B & 2,6 a B \\
\hline E1 & 9,5 a $A$ & $3,1 \mathrm{~b} \mathrm{~B}$ & 3,1 a B \\
\hline E2 & $5,8 \mathrm{~b} \mathrm{~B}$ & 7,8 a $\mathrm{A}$ & 1,9 a C \\
\hline E3 & $6,7 \mathrm{~b} \mathrm{~A}$ & 0,0 с C & 2,9 a B \\
\hline
\end{tabular}

C.V. $(\%)$ 22,5

Médias seguidas da mesma letra minúscula para manejo e épocas, e maiúscula para ceifas, não diferem entre si significativamente a 5\% de probabilidade pelo teste Tukey. 
Quanto às épocas de semeadura, na $E_{1}$ e $E_{3}$, a primeira ceifa $\left(C_{1}\right)$ proporcionou maior produção de restos vegetais que nas ceifas das rebrotas $\left(C_{2}\right.$ e $\left.C_{3}\right)$, enquanto para $E_{2}$, a ceifa da primeira rebrota $\left(C_{2}\right)$ foi a que produziu maior quantidade de restos vegetais (Quadro 4). Em $\mathrm{E}_{2}$ as chuvas favoreceram o desenvolvimento da primeira rebrota (Figura 1), resultando em maior número de colmos na ceifa $C_{2}$ que na $C_{1}$ e conseqüentemente na maior quantidade de resto vegetal em $C_{2}$.

Nas três épocas de semeadura, a menor produção de resto vegetal apresentada pela ceifa de manejo final (na média dos manejos $\mathrm{M}_{1}$ e $\mathrm{M}_{2}$ ) está relacionada ao longo período de estiagem (em torno de um mês) após a ceifa anterior acompanhada por períodos de baixas temperaturas (Figura 1).
Analisando-se o total de resto vegetal produzido pelos diferentes manejos, dentro de cada época, não se observou diferença entre eles (Quadro 5). Todavia, a análise conjunta das três épocas, mostrou menor produção no manejo $\mathrm{M}_{5}$, de livre crescimento, enquanto as produções não diferiram significativamente.

Com relação às épocas de semeadura, verificou-se que, com o atraso, houve diminuição da produção de resto vegetal total produzido, com redução acentuada em $E_{3}$. Essa redução está de acordo com os resultados obtidos por outros autores, tendo sido atribuída a fatores como fotoperíodo, baixa temperatura e pouca precipitação pluvial (LIRA et al., 1977; WestPHALEN e JACQUes, 1978; SCALÉA, 1999).

Quadro 5. Dados de produção total de restos vegetais de milheto, obtidos para os diferentes manejos $M_{1^{\prime}}, M_{2^{\prime}}, M_{3^{\prime}}, M_{4^{\prime}}, M_{5^{\prime}}$ para as três épocas de semeadura $\left(\mathrm{E}_{1}, \mathrm{E}_{2}, \mathrm{E}_{3}\right)$. Botucatu, 1999

\begin{tabular}{|c|c|c|c|c|}
\hline \multirow{3}{*}{ Manejo } & \multicolumn{4}{|c|}{ Épocas de semeadura } \\
\hline & E1 & $\mathrm{E} 2$ & E3 & Média \\
\hline & \multicolumn{4}{|c|}{ Produção de restos vegetais } \\
\hline & \multicolumn{4}{|c|}{$\mathrm{t} \mathrm{ha}^{-1}$} \\
\hline M1 & $15,14 \mathrm{a}^{(1)}$ & $15,1 \mathrm{a}$ & 8,9 a & $13,0 \mathrm{ab}$ \\
\hline M2 & $16,4 \mathrm{a}$ & $16,1 \mathrm{a}$ & $10,4 \mathrm{a}$ & 14,3 a \\
\hline M3 & 17,4 a & $17,3 \mathrm{a}$ & $11,2 \mathrm{a}$ & $15,3 \mathrm{a}$ \\
\hline M4 & $14,9 \mathrm{a}$ & $14,3 \mathrm{a}$ & $11,3 \mathrm{a}$ & $13,5 \mathrm{ab}$ \\
\hline M5 & 15,6 a & $11,7 \mathrm{a}$ & 7,2 a & $11,5 \mathrm{~b}$ \\
\hline Média & $15,9 \mathrm{~A}$ & $14,9 \mathrm{~A}$ & $9,8 \mathrm{~B}$ & \\
\hline C.V. $(\%)$ & 13,3 & 16,9 & 19,1 & \\
\hline
\end{tabular}

Médias seguidas da mesma letra minúscula para manejos e maiúscula para épocas, não diferem entre si significativamente a 5\% de probabilidade pelo teste Tukey.

Quadro 6. Dados de produção total de restos vegetais de milheto, deixados em cobertura no solo, obtidos nos diferentes manejos $M_{1}, M_{2}, M_{3}, M_{4}, M_{5}$, para as três épocas de semeadura $\left(E_{1}, E_{2}, E_{3}\right)$. Botucatu, 1999

\begin{tabular}{|c|c|c|c|c|}
\hline \multirow{3}{*}{ Manejos } & \multicolumn{4}{|c|}{ Épocas de semeadura } \\
\hline & E1 & E2 & E3 & Média \\
\hline & \multicolumn{4}{|c|}{ Restos vegetais em cobertura } \\
\hline & 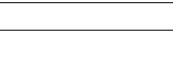 & 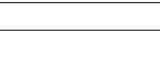 & thes & \\
\hline M1 & $3,2 \mathrm{~b} \mathrm{~A}^{(1)}$ & $2,0 \mathrm{~b} \mathrm{~A}$ & $2,8 \mathrm{~b} \quad \mathrm{~A}$ & $2,7 \mathrm{c}$ \\
\hline M2 & 16,4 a $\mathrm{A}$ & 16,1 a $A$ & 10,4 a $\mathrm{B}$ & 14,3 a \\
\hline M3 & 7,4 b B & 11,4 a $\mathrm{A}$ & $3,0 \mathrm{~b} \quad \mathrm{C}$ & $7,3 \mathrm{~b}$ \\
\hline M4 & 14,9 a $\mathrm{A}$ & 14,3 а $\mathrm{AB}$ & 11,3 a $\mathrm{B}$ & $13,5 \mathrm{a}$ \\
\hline M5 & 15,6 a $\mathrm{A}$ & 11,7 a $B$ & $7,2 \mathrm{ab} C$ & $11,5 \mathrm{a}$ \\
\hline
\end{tabular}

C.V. $(\%)$ 20,4

Médias seguidas da mesma letra minúscula para manejos e maiúscula para épocas, não diferem entre si significativamente a 5\% de probabilidade pelo teste Tukey. 
A cultura da soja foi instalada em sucessão ao milheto que, em vista dos manejos, resultaram em diferentes quantidades de fitomassa residuais em cobertura no solo (Quadro 6). Cabe ressaltar que os manejos $\mathrm{M}_{1}$ e $\mathrm{M}_{3}$, para as três épocas de semeadura do milheto, deixaram menor quantidade de restos vegetais, pois como foram retirados por ocasião das ceifas, restaram apenas as rebrotas que permaneceram no manejo final. Assim como ocorreu para o resto vegetal total, a terceira época $\left(\mathrm{E}_{3}\right)$ apresentou a menor quantidade de restos vegetais sobre o solo.

As diferenças de quantidade de resto vegetal de milheto nos manejos e nas épocas não resultaram em modificações evidentes no desenvolvimento da cultura da soja cultivada em sucessão, tanto na ocorrência dos principais estádios de desenvolvimento (FeHr et al. 1971) como na duração do ciclo (Figura 2).

A população de plantas de soja obtida por ocasião da colheita mostrou-se correlacionada positivamente $\left(r=0,659^{* *}\right)$ com os restos vegetais de milheto, ou seja, maiores populações finais foram observadas naqueles, com maior quantidade de palha da cultura anterior. Esse fato mostra que a resteva de milheto proporcionou condições favoráveis para obter e preservar a população de plantas de soja, nas condições em que se manejou o resto vegetal (Quadro 7). A altura da planta, altura de inserção da primeira va- gem, o número total de vagens por planta e número de vagens normais por planta da soja (Quadro 8) não foram afetados pelos manejos e restos vegetais nem pelas épocas de semeadura do milheto. Já o número de vagens chochas por plantas, porcentagem de vagens chochas e massa de 100 grãos não foram afetados pelos manejos, mas sim pelas épocas (Quadros 8 e 9).

A época $E_{1}$ propiciou maior número e porcentagem de vagens chochas por planta e de massa de 100 grãos. Por sua vez, a $\mathrm{E}_{3}$ apresentou menor porcentagem e número de vagens chochas. Em trabalhos nos quais se estudaram os efeitos da cultura anterior de inverno sobre características e componentes da produção de soja, foram observados efeitos ou não em vista das espécies (Santos e Pereira, 1987; Santos e Reis, 1990; SANTOS, 1991).

Quanto à produtividade de grãos da soja, a análise conjunta das épocas mostrou que após o manejo $\mathrm{M}_{1}$ de milheto houve menor produtividade, enquanto o manejo $\mathrm{M}_{4}$ proporcionou o maior rendimento (Quadro 9). Estes resultados são justificados pelos componentes da produção, pois para $\mathrm{M}_{4}$ obteve-se os maiores valores para número de vagens por planta, massa de 100 grãos e produção de grãos por planta, enquanto para $\mathrm{M}_{1}$, o menor valor para massa de 100 grãos, embora sem diferirem significativamente dos demais manejos.

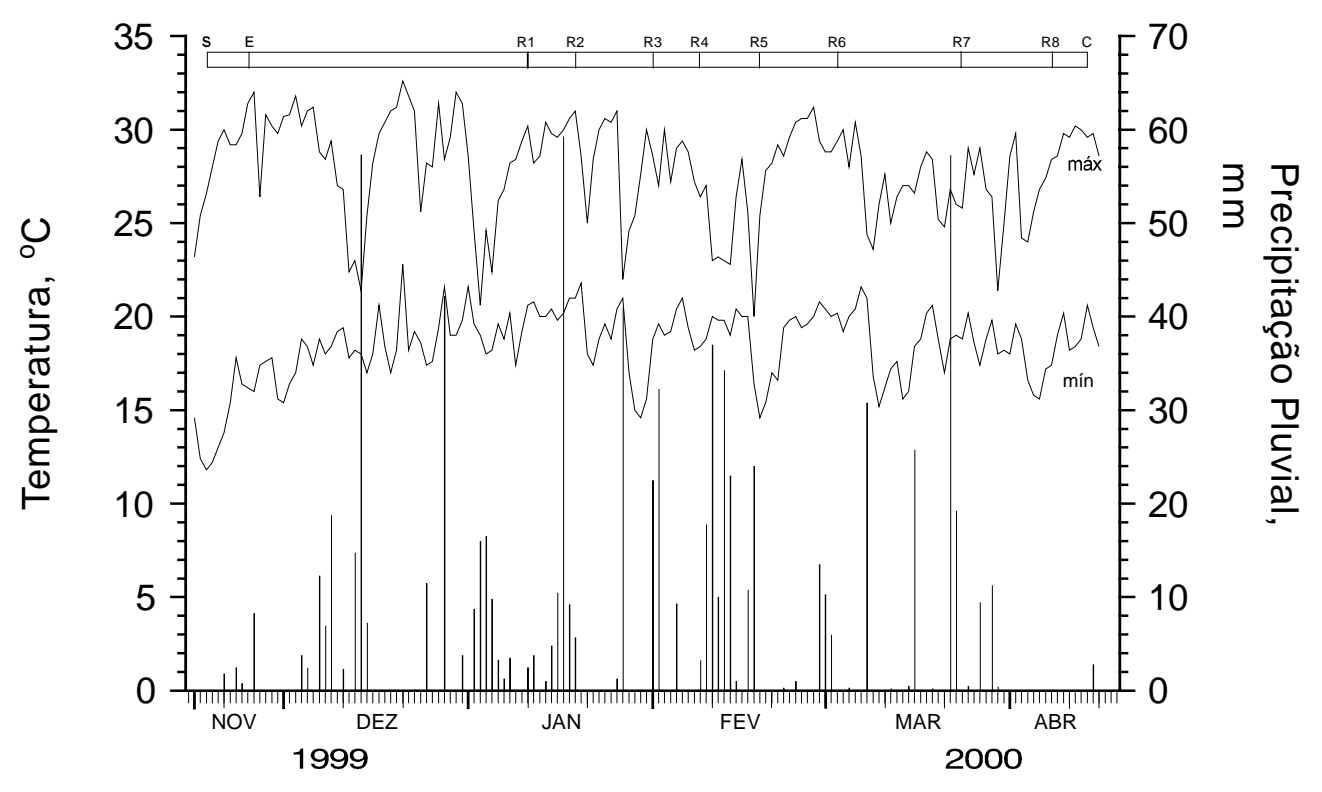

Figura 2. Ciclo cultural e estádio de desenvolvimento da soja cv. EMBRAPA-48, semeada após milheto. Dados diários de precipitação pluvial e temperaturas máxima e mínima. $\mathrm{S}=$ semeadura; $\mathrm{E}=$ emergência de plântulas; $\mathrm{C}=$ colheita; R1,..., R8 = estádios reprodutivos segundo Fehr et al. (1971). Botucatu, 2000. 
Quadro 7. Dados da população final de plantas de soja cultivada em sucessão ao milheto semeado em três épocas e com diferentes manejos da parte aérea $\left(M_{1}, M_{2}, M_{3}, M_{4}, M_{5}\right)$. Botucatu, 2000

\begin{tabular}{|c|c|c|c|c|}
\hline \multirow{3}{*}{ Manejos } & \multicolumn{4}{|c|}{ Épocas de semeadura } \\
\hline & E1 & E2 & E3 & Média \\
\hline & \multicolumn{4}{|c|}{ População (mil plantas ha ${ }^{-1}$ ) } \\
\hline M1 & $212 \mathrm{a}$ & $183 \mathrm{a}$ & $186 \mathrm{a}$ & $194 \mathrm{a}$ \\
\hline M2 & $223 a$ & $212 \mathrm{a}$ & $198 \mathrm{a}$ & $211 \mathrm{a}$ \\
\hline M3 & $221 \mathrm{a}$ & $197 \mathrm{a}$ & $191 \mathrm{a}$ & $203 a$ \\
\hline M4 & $243 a$ & $208 \mathrm{a}$ & $223 \mathrm{a}$ & $225 \mathrm{a}$ \\
\hline M5 & $252 \mathrm{a}$ & $201 \mathrm{a}$ & $179 \mathrm{a}$ & $211 \mathrm{a}$ \\
\hline Média & $230 \mathrm{~A}$ & $200 \mathrm{~B}$ & $195 \mathrm{C}$ & \\
\hline C.V. $(\%)$ & \multicolumn{4}{|c|}{8,70} \\
\hline
\end{tabular}

Médias seguidas da mesma letra minúscula para manejos e maiúscula para épocas, não diferem entre si significativamente a 5\% de probabilidade pelo teste Tukey.

Quadro 8. Análise conjunta do experimento de soja em sucessão a três épocas de semeadura $\left(E_{1}, E_{2}, E_{3}\right)$ de milheto com diferentes manejos da parte aérea $\left(\mathrm{M}_{1}, \mathrm{M}_{2}, \mathrm{M}_{3}, \mathrm{M}_{4}, \mathrm{M}_{5}\right)$ para parâmetros de soja. Botucatu, 2000

\begin{tabular}{|c|c|c|c|c|c|}
\hline Manejo/Época & $\begin{array}{c}\text { Altura } \\
\text { da planta }\end{array}$ & $\begin{array}{c}\text { Altura inserção } \\
1 .^{a} \text { vagem }\end{array}$ & $\begin{array}{l}\text { Total vagem } \\
\text { por planta }\end{array}$ & $\begin{array}{c}\text { Vagem } \\
\text { normal/planta }\end{array}$ & $\begin{array}{c}\text { Vagens } \\
\text { chochas / } \\
\text { planta }\end{array}$ \\
\hline & \multicolumn{5}{|c|}{$\overline{\mathrm{cm}} \longrightarrow$} \\
\hline M1 & 80,1 a & $18,5 \mathrm{a}$ & $74,1 \mathrm{a}$ & $67,5 \mathrm{a}$ & $6,5 \mathrm{a}$ \\
\hline M2 & $87,1 \mathrm{a}$ & $19,0 \mathrm{a}$ & $71,5 \mathrm{a}$ & $67,2 \mathrm{a}$ & $4,3 \mathrm{a}$ \\
\hline M3 & 85,9 a & $20,1 \mathrm{a}$ & 68,5 a & 63,5 a & $5,0 \mathrm{a}$ \\
\hline M4 & 87,3 a & $18,1 \mathrm{a}$ & 81,0 a & $74,4 \mathrm{a}$ & $6,6 \mathrm{a}$ \\
\hline M5 & 83,7 a & $19,5 \mathrm{a}$ & $65,1 \mathrm{a}$ & $61,2 \mathrm{a}$ & 3,9 a \\
\hline E1 & $85,6 \mathrm{~A}$ & $20,2 \mathrm{~A}$ & $66,2 \mathrm{~A}$ & $60,1 \mathrm{~A}$ & $6,1 \mathrm{~A}$ \\
\hline E2 & $84,6 \mathrm{~A}$ & $18,3 \mathrm{~A}$ & $71,8 \mathrm{~A}$ & $66,1 \mathrm{~A}$ & $5,6 \mathrm{AB}$ \\
\hline E3 & $84,3 \mathrm{~A}$ & $18,7 \mathrm{~A}$ & $78,2 \mathrm{~A}$ & $74,1 \mathrm{~A}$ & $4,0 \mathrm{~B}$ \\
\hline C.V. $(\%)$ & 9,3 & 12,9 & 14,0 & 13,9 & 27,0 \\
\hline
\end{tabular}

Médias na coluna, seguidas da mesma letra minúscula para manejos e maiúscula para épocas, não diferem entre si significativamente a 5\% de probabilidade pelo teste Tukey.

Quadro 9. Análise conjunta dos três experimentos de soja em sucessão a três épocas de semeadura $\left(\mathrm{E}_{1}, \mathrm{E}_{2^{\prime}} \mathrm{E}_{3}\right)$ de milheto com diferentes manejos da parte aérea $\left(M_{1}, M_{2}, M_{3}, M_{4}, M_{5}\right)$, para parâmetros de soja. Botucatu, 2000

\begin{tabular}{lccc}
\hline Manejo/Época & Vagens chochas & Massa de 100 grãos & Produtividade de grãos \\
\hline & $\%$ & $\mathrm{~g}$ & $2.468 \mathrm{~b}$ \\
M1 & $8,7 \mathrm{a}$ & $16,8 \mathrm{a}$ & $2.882 \mathrm{ab}$ \\
M2 & $6,1 \mathrm{a}$ & $17,3 \mathrm{a}$ & $2.844 \mathrm{ab}$ \\
M3 & $7,1 \mathrm{a}$ & $17,1 \mathrm{a}$ & $3.104 \mathrm{a}$ \\
M4 & $8,2 \mathrm{a}$ & $17,4 \mathrm{a}$ & $2.782 \mathrm{ab}$ \\
M5 & $6,4 \mathrm{a}$ & $17,2 \mathrm{a}$ & $3.011 \mathrm{~A}$ \\
E1 & $9,1 \mathrm{~A}$ & $17,6 \mathrm{~A}$ & $2.451 \mathrm{~B}$ \\
E2 & $7,8 \mathrm{~A}$ & $16,7 \mathrm{~B}$ & $2.985 \mathrm{~A}$ \\
E3 & $5,0 \mathrm{~B}$ & $17,2 \mathrm{AB}$ & 16,3 \\
\hline C.V. (\%) & 21,4 & 5,3 & \\
\hline
\end{tabular}

Médias na coluna, seguidas da mesma letra minúscula para manejos e maiúscula para épocas, não diferem entre si significativamente a $5 \%$ de probabilidade pelo teste Tukey. 
A população final de plantas da soja (Quadro 7) foi o componente que mais contribuiu para estes resultados, tendo-se correlacionado positivamente com a produtividade de grãos de soja $\left(r=0,926^{*}\right)$. Com relação ao efeito de época na produtividade de grãos, verificou-se que a $E_{1}$ apresentou menor produção por planta, mas maior população de plantas, e $\mathrm{E}_{3}$ a menor população de plantas mas a maior produção por planta, resultando em maior produtividade nessas duas épocas. Em trabalhos com soja tem-se observado efeito dos tratamentos, nos componentes de produção, porém não na produtividade e às vezes não influenciam os componentes causando efeito na produtividade (Santos e Pereira, 1987; Santos e Reis, 1990; SANTOS et al., 1994).

\section{CONCLUSÕES}

1. As maiores produções de restos vegetais do milheto foram obtidas em semeaduras de março e nos manejos com ceifa;

2. As maiores produções de grãos da soja foram obtidas quando se cultivou em sucessão a primeira e terceira épocas de semeadura de milheto (5 de março e 19 de abril).

\section{REFERÊNCIAS BIBLIOGRÁFICAS}

BURGER, A.W. Crop Classification. In: TESAR, M.B. (Ed.). Physiological basis of crop growth and development. Madison: American Society of Agronomy, 1984. p.1-12.

CASTRO, O.M.; LOMBARDI NETO, F.; QUAGGIO, J.A.; DE MARIA, I.C.; VIEIRA, S.R.; DECHEN, S.C.F. Perdas por erosão de nutrientes vegetais na sucessão soja/trigo em diferentes sistemas de manejo. Revista Brasileira de Ciência do Solo, Campinas, v.10, p.293-297, 1986.

DEDECEK, R.A.; RESK, D.V.S.; FREITAS JUNIOR, E. Perdas de solo, água e nutrientes por erosão em latossolo vermelhoescuro dos cerrados em diferentes cultivos sob chuva natural. Revista Brasileira de Ciência do Solo, Campinas, v.10, p.265-272, 1986.

EMBRAPA, Centro Nacional de Pesquisa de Solo. Sistema Brasileiro de Classificação dos Solos. Rio de Janeiro: EMBRAPA/CNPS, 1997. 212p.

FEHR, W. R.; CAVINESS, C. E.; BURMOOD, D. T.; PENNINGTON, J. S. Stage of development descriptions for soybeans, Glycine $\max ($ L.) Merrill. Crop Science, Madison, v.11, p. 929-931, 1971.

FERRARIS, R.; NORMAN, M. J. T. Factors affecting the regrowth of Pennisetum americanum vuder frequent defoliation. Australian Journal of Agricultural Research, East Melbourne, v.27, p. 365-371, 1976.
HERNANI, L.C.; SALTON, J.C. Manejo do Solo. In: RECOMENDAÇÕES Técnicas para Mato Grosso do Sul e Mato Grosso. Dourados: EMBRAPA, 1996. p.34-53.

LANDERS, J.N. Fascículo de experiências de plantio direto no cerrado. Goiânia: APDC, 1995. 261p.

LIRA, M.A.; FARIS, M. A.; TABOSA, J.N.; REIS, O.V. Estudos preliminares sobre o efeito da época de plantio e da aplicação de adubos na produção de grão de milheto, do sorgo e do milho. Pesquisa Agropecuária Pernambucana, Recife, v.1, n.1, p.89103, 1977.

LOMBARDI NETO, F.; DE MARIA, I.C.; CASTRO, O.M.; DECHEN, S.C.F.; VIEIRA, S.R. Efeito da quantidade de resíduos culturais de milho nas perdas de solo e água. Revista Brasileira de Ciência do Solo, Campinas, v.12, p.71-75, 1988.

LOPES, P.R.C.; COGO, N.P.; LEVIEN, R. Eficácia relativa de tipo e quantidade de resíduos culturais espalhados uniformemente sobre o solo na redução da erosão hídrica. Revista Brasileira de Ciência do Solo, Campinas, v.11, p.71-75, 1987.

PEREIRA, J.A.R. Cultivo de espécies visando à obtenção de cobertura vegetal do solo na entressafra da soja (Glycine max (L.) Merrill) no cerrado. 1990. 83f. Dissertação (Mestrado em Agronomia - Área de Concentração Agricultura) - Faculdade de Ciências Agronômicas, Universidade Estadual Paulista, Botucatu.

RAIJ, van. B.; QUAGGIO, J.A. Métodos de análise de solo para fins de fertilidade. Campinas: Instituto Agronômico, 1983. 31p. (Boletim Técnico, 81).

SALTON, J.C. Opções de safrinha para agregação de renda nos cerrados. In: PLANTIO direto na integração lavoura-pecuária. Uberlândia: APDC, 2001. p.189-200.

SANTOS, H.P. Soja em sucessão a aveia branca, aveia preta, azevém e trigo: Características agronômicas. Pesquisa Agropecuária Brasileira, Brasília, v.26, n.9, p.1563-1576, 1991.

SANTOS, H.P.; PEREIRA, L. R. Rotação de culturas. VII. Efeito de culturas de inverno sobre o rendimento de grãos e algumas características agronômicas das plantas de soja, no período de 1975 a 1985. Pesquisa Agropecuária Brasileira, Brasília, v.22, n.1, p.63-70, 1987.

SANTOS, H. P.; PEREIRA, L. R.; REIS, E. M. Rotação de culturas em Guarapuana. XII. Efeitos de sistemas de sucessão de culturas sobre o rendimento de grãos e sobre outras características agronômicas da soja, em plantio direto. Pesquisa Agropecuária Brasileira, Brasília, v.29, n.6, p. 907 - 916, 1994.

SANTOS, H. P.; REIS, E. M. Rotação de culturas. XIX. Efeitos de culturas de inverno sobre o rendimento de grãos e sobre algumas características agronômicas da soja. Pesquisa Agropecuária Brasileira, Brasília, v.25, n.11, p.1637-1645, 1990.

SCALÉA, M. A cultura do milheto e seu uso no plantio direto no cerrado. In: WORKSHOP INTERNACIONAL DE MILHETO. FARIAS NETO, A. L.; AMABILE, R. F.; MARTINS NETO, D. A.; YAMASHITA, T.; GOCHO, H. (Editores). Anais... Planaltina: Embrapa Cerrados, 1999. p.75-82. 
SEIFFERT, N. F.; BARRETO, I.L. Forrageiras para ensilagem. I. Avaliação de cultivares de milho (Zea mays L.), sorgo (Sorgnun sp.) e milheto ( Pennisetum americanum Schum.) na região da Depressão Central do Rio Grande do Sul. Agronomia Sulriograndense, Porto Alegre, v.13, p. 205-214, 1977.

SILVA, I.F.; ANDRADE, A.P.; CAMPOS FILHO, C.R.; OLIVEIRA, F.A.P. Efeito de diferentes coberturas vegetais e de práticas conservacionistas no controle da erosão. Revista Brasileira de Ciência do Solo, Campinas, v.10, p.289-292, 1986.
WESTPHALEN, S. L.; JACQUES, A. V. A. Efeitos de época de semeadura estádio de crescimento e altura de corte sobre rendimento de matéria seca e proteína bruta de milheto Pérola. 1. Cultivar de floração tardia. Agronomia Sulriograndense, Porto Alegre, v.14, n.1, p.87-106, 1978. 